Recebido em 22 de Maio de 2017 Aceito em 10 de Outubro de 2017 Autor para contato: anapauladfernandes@yahoo.com.br

\title{
Resumo
}

\section{Aspectos socioculturais e econômicos na área de proteção ambiental (APA) de Guaratuba, Paraná}

Sociocultural and economic aspects in the environmental protection area of Guaratuba, Paraná

Ana Paula Donicht Fernandes

Universidade Federal Rural da Amazônia - UFRA - Capitão Poço - Pará - Brasil

Ivan Crespo Silva

Vitor Afonso Hoeflich

Universidade Federal do Paraná - UFPR - Curitiba - Paraná - Brasil

Mara Freire Rodrigues de Souza

Rodrigues de Souza Sociedades Individual de Advocacia

\begin{abstract}
A Mata Atlântica é um dos biomas mais importantes do Brasil e abriga populações tradicionais de caboclos e caiçaras. Este artigo analisa o perfil dos moradores tradicionais das quatro unidades de gestão nos limites da Área de Proteção Ambiental (APA) de Guaratuba, no município de Guaratuba. A coleta de dados foi feita a partir de entrevistas com 70 famílias moradoras da APA. Os resultados demonstram que os moradores da APA, em sua maioria, podem ser caracterizados como tipicamente de unidade familiar, pois possuem propriedades com até 4 módulos fiscais e a maior parte da mãode-obra é constituída por membros da família. O sistema de produção agrícola está presente em mais de $80 \%$ das propriedades, sendo que a banana se configura como a principal cultura da região. A produção florestal foi caracterizada por extrativismo em florestas nativas (59\%), extrativismo em florestas plantadas (37\%) e em produção madeireira (6\%). Com relação aos instrumentos de políticas públicas, o crédito rural foi acessado por apenas $24,3 \%$ dos entrevistados e $41,42 \%$ relataram receber assistência técnica. A associação dos bananicultores é utilizada principalmente para assistência técnica, compra de insumos na produção e emissão do Certificado Fitossanitário de Origem. Não foram identificadas organizações para comercialização ou produção de produtos florestais não madeireiros. Conclui-se que a APA de Guaratuba possui um contexto sociocultural e econômico que pouco favorece o desenvolvimento das comunidades locais sendo imperioso o planejamento e elaboração de políticas públicas que assegurem a proteção da biodiversidade e o respeito à cultura das comunidades locais.
\end{abstract}

\section{Abstract}

The Atlantic Forest is one of the most important biomes in Brazil and in the tropical region, and shelters traditional populations of caboclos and caiçaras. This article analyzes the profile of the traditional residents of the four management units within the boundaries of the Guaratuba Environmental Protection Area (EPA), in the municipality of Guaratuba. Data collection was done based on interviews with 70 families living in the EPA. The results show that residents, for the most part, can be characterized as typically family units, since they have properties with up to 4 fiscal modules and most of the workforce is made up of family members. Regarding economic issues, the agricultural production system is present in more than $80 \%$ of the properties visited, with banana being the main culture of the region. Forest production was characterized by extractivism in native forests (59\%), extractivism in planted forests (37\%) and timber production (6\%). Regarding public policy instruments, rural credit was accessed by only $24.3 \%$ of respondents and $41.42 \%$ reported receiving technical assistance. The association of banana growers is used mainly for technical assistance, purchase of inputs in production and issuance of the Phytosanitary Certificate of Origin. No organizations have been identified for commercialization or production of non-timber forest products. It is concluded that the APA of Guaratuba has a socio-cultural and economic context that does not favor the development of local communities, being imperative the planning and elaboration of public policies that ensure the protection of biodiversity and respect to the culture of local communities.

\section{Palavras-chave}

Comunidade tradicional. Saber popular. Governança florestal. Política pública.

\section{Keywords}

Traditional communities. Popular knowledge. Forest governance. Public policy. 


\section{Introdução}

No Brasil, a área coberta pela Mata Atlântica tem reduzido ao longo dos séculos devido ao extrativismo predatório, à ação transformadora da floresta em área agrícola e à especulação imobiliária. No entanto, ainda compõe uma região de riquíssimo patrimônio reunindo em seu entorno milhões de habitantes, muitos dos quais dependem da exploração dos recursos naturais disponíveis (SIMÕES; LINO, 2002).

A Mata Atlântica presente no município de Guaratuba é protegida em sua totalidade pela Área de Proteção Ambiental (APA) de Guaratuba, que engloba todo o município de Guaratuba e parte dos municípios de Matinhos, Tijucas do Sul, São José dos Pinhais e Morretes (PARANÁ, 2006). O Plano de Manejo da APA de Guaratuba é o primeiro documento no âmbito das APAs estaduais no Paraná a ser efetivamente concretizado, ressaltando mais ainda sua importância. Inseridos no plano de manejo, o mapa do zoneamento ecológico econômico separados por zonas de conservação, são apresentados em três unidades de gestão: Unidade Baía de Guaratuba, Unidade Limeira-Cubatão e Unidade BR-376 (PARANÁ, 2006).

A APA de Guaratuba está localizada no centro nas coordenadas 25\%47'25.04" de latitude e 484' $25.53^{\prime \prime}$ de longitude e possui 199,569 hectares de superfície. As principais atividades desenvolvidas na área são: Agricultura familiar; agricultura moderna ou comercial; pecuária familiar; exploração mineral; pesca; agroindústria - fabricação de produtos alimentícios; prestação de serviços (chácaras); extrativismo animal (caça); extrativismo florestal (ornamentais, bromélias, xaxins, palmito).

Sonda (2002) definiu como sendo característicos destas populações, o conhecimento dos ciclos biológicos, a utilização dos recursos naturais e hábitos alimentares. Esse "saber fazer" tradicional, que vem de geração em geração é um instrumento importante para a conservação desses recursos. São pessoas cuja origem étnica mescla basicamente o indígena, o português e o negro, que formam a base do povo do litoral, denominado de caboclo ou caiçara.

Assim, para o Program on Forests (PROFOR, 2011, p.7), "a qualidade da governança determina o quanto os recursos florestais serão utilizados de forma eficiente, sustentável e equitativo". A governança florestal inclui as normas, processos, instrumentos e organizações que controlam como as pessoas interagem com as florestas, gerindo os recursos florestais com critérios de sustentabilidade (PROFOR, 2011). Portanto, o processo de planejamento é um processo de decisão política que depende de informações precisas, transparência, ética, temperança, aceitação de visões diferentes e vontade de negociar e buscar soluções conjuntamente que sejam aceitáveis para toda a sociedade e principalmente para as partes envolvidas (OLIVEIRA, 2006).

A participação da sociedade civil tem como intuito prioritário o atendimento as suas demandas. Sabendo que o Estado, por si só, não atende a todas as pessoas, o engajamento social da população acaba por desenvolver movimentos próprios no sentido de buscar modificar a realidade, tentando provocar pequenas transformações. Neste contexto, objetivase descrever o perfil da população residente nos limites da APA de Guaratuba a fim de permitir a elaboração de políticas públicas que visem a integração e desenvolvimento da população local.

\section{Material e métodos}

A amostragem probabilística é fortemente condicionada pela existência prévia de um cadastro sem falhas (LEITE et al., 2004). Considerando-se a inexistência do pré-requisito indicado, optou-se pela amostragem não probabilística por conveniência que é aquela em que a seleção dos elementos da população para compor a amostra depende ao menos em parte do julgamento do pesquisador ou do entrevistador no campo (MATTAR, 1996). Assim, dada à extensão territorial que a pesquisa cobriu, optou-se pela definição de uma fração fixa de $10 \%$ 
das famílias por unidade de gestão. $\mathrm{O}$ total de famílias agricultoras rurais em cada unidade de gestão é apresentado no quadro 1.

Quadro 1. Número total de famílias por comunidade

\begin{tabular}{|c|c|c|}
\hline Unidades de Gestão & Comunidades & $\mathbf{N}^{\circ}$ total de famílias \\
\hline Caovi-Limeira & $\begin{array}{l}\text { São João Abaixo } \\
\text { Caovi } \\
\text { Taquaruvu } \\
\text { Rio do Melo } \\
\text { Vitório } \\
\text { Pai Paulo } \\
\text { Cubatão } \\
\text { Salto do Cubatão } \\
\text { Rasgado } \\
\text { Rasgadinho } \\
\text { Ribeirão do Engenho } \\
\text { Ribeirão Grande } \\
\text { Limeira }\end{array}$ & $\begin{array}{l}270 \text { famílias agricultoras } \\
\text { rurais }\end{array}$ \\
\hline Morro Grande & $\begin{array}{l}\text { Estaleiro } \\
\text { Riozinho } \\
\text { Jundiaquara } \\
\text { São Joãozinho } \\
\text { Descoberto } \\
\text { Cedro } \\
\text { Empanturrado } \\
\text { Rio do Saco }\end{array}$ & $\begin{array}{l}200 \text { famílias agricultoras } \\
\text { rurais }\end{array}$ \\
\hline Estrada do Castelhano & $\begin{array}{l}\text { Castelhano } \\
\text { Alto da Serra } \\
\text { Potreiro } \\
\text { Rio Bonito } \\
\text { Pedra Branca do Araraquara }\end{array}$ & $\begin{array}{l}100 \text { famílias agricultoras } \\
\text { rurais }\end{array}$ \\
\hline Baia de Guaratuba & $\begin{array}{l}\text { Parati } \\
\text { Fincão }\end{array}$ & $\begin{array}{l}30 \text { famílias agricultoras } \\
\text { rurais }\end{array}$ \\
\hline
\end{tabular}

Fonte: Elaborado pelos autores (2017)

A definição do total de número de famílias agricultoras foi baseada no relatório de realidade municipal da EMATER de Guaratuba. Na data em que as entrevistas foram realizadas, o Instituto de Terras Cartografia e Geociências do Paraná estava em processo de demarcação para o Cadastro Ambiental Rural (CAR).

A coleta de dados foi baseada em entrevistas com famílias moradoras da APA de Guaratuba, das três unidades de gestão: BR 376, Limeira-Cubatão e Baia de Guaratuba, além da localidade Morro Grande não presente no plano de manejo da APA de Guaratuba (Quadro 2). A coleta dos dados foi conduzida durante os meses de agosto, setembro e outubro de 2016 com o apoio logístico/institucional das equipes da EMATER Paraná e do Instituto de Florestas do Paraná em Guaratuba. 
Quadro 2. Número total de entrevistas realizadas.

\begin{tabular}{l|l|l|}
\multicolumn{1}{|c|}{ Unidade de Gestão } & \multicolumn{1}{|c|}{$\begin{array}{c}\text { No total de famílias } \\
\text { agricultoras }\end{array}$} & $N^{\circ}$ de entrevistas realizadas \\
\hline Caovi-Limeira & 270 & $31(11,5 \%)$ \\
\hline Morro Grande & 200 & $22(11,0 \%)$ \\
\hline Estrada do Castelhano & 100 & $13(13,0 \%)$ \\
\hline Baia de Guaratuba & 30 & $4(13,3 \%)$ \\
\hline Total & 600 & $70(11,6 \%)$ \\
\hline
\end{tabular}

Fonte: Elaborado pelos autores (2017)

As entrevistas seguiram o roteiro de questionários semiestruturados visando a obtenção de três conjuntos de informações: a) questões socioeconômicas; b) aspectos relacionados à utilização da terra e dos recursos naturais (oportunidades e entraves); c) percepção do processo político e a influência e/ou responsabilidade dos atores na tomada de decisões no setor.

As entrevistas semiestruturadas combinam questões abertas e fechadas permitindo que o entrevistado discorra, de forma mais detalhada, em relação ao tópico da entrevista. Este método proporciona maior interação entre entrevistador e entrevistado (BONI e QUARESMA, 2005).

O método de pesquisa teve como base os princípios do Diagnóstico Rural Participativo (DRP). As técnicas utilizadas são preconizadas nos DRPs e constituem em: entrevistas estruturadas com pessoas-chave; reuniões com a comunidade para explicar o objetivo do trabalho e complementar informação com a triangulação de informações (checagem de fontes de consulta), a partir de reuniões com técnicos da Empresa de Assistência Técnica e Extensão Rural - EMATER, Instituto de Florestas do Paraná, Instituto Ambiental do Paraná - IAP e Prefeitura Municipal.

Após a coleta dos dados, todas as respostas relacionadas com cada tópico, foram transferidas para uma tabela do Excel. Cada entrevistado utiliza de diferentes formas de expressão para responder cada pergunta; no entanto, claras similaridades foram identificadas em cada resposta, possibilitando o agrupamento das respostas similares.Para a caracterização dos produtos não madeireiros extraídos pelas famílias, as frequências relativa e absoluta foram calculadas para cada resposta. A frequência relativa foi calculada baseada no total de respostas para cada tópico, totalizando $100 \%$.

\section{Resultados e discussões}

Foram entrevistados 70 agricultores rurais nas quatro unidades de gestão da APA de Guaratuba, e os principais resultados com relação as características sociais e econômicas dos agricultores rurais que residem nos limites da APA de Guaratuba, estão descritas de forma conjunta.

\section{Aspectos Sociais}

Os 70 agricultores rurais entrevistados vivem hoje em uma área total de 2.023,13 hectares, dos quais $82 \%$ foram declarados como área de floresta. De acordo com os dados da 
pesquisa de campo (Quadro 3 ), percebe-se que a maioria das propriedades rurais $(77,14 \%)$ se caracteriza como pequena propriedade (até 4 módulos fiscais), sendo que o módulo fiscal para o município de Guaratuba é de 16 hectares.

Quadro 3. Estrutura fundiária

\begin{tabular}{|l|r|r|}
\hline Estratos de área & $\mathbf{N}^{\circ}$ de propriedades & Frequência (\%) \\
\hline Não possui área própria & 4 & 5,71 \\
\hline até 16 ha & 40 & 57,14 \\
\hline de 16,1 ha a 64 ha & 14 & 20,00 \\
\hline de 64,1 ha a 240 ha & 10 & 14,29 \\
\hline$>240$ ha & 1 & 1,43 \\
\hline Não respondeu & 1 & 1,43 \\
\hline Total & $\mathbf{7 0}$ & $\mathbf{1 0 0 , 0 0}$ \\
\hline
\end{tabular}

Fonte: Elaborado pelos autores (2017).

No período do levantamento realizado, $45,72 \%$ das famílias possuíam apenas a posse das terras onde residem e trabalham. A maioria dos produtores adotavam práticas típicas de pequena agricultura ou agricultura familiar (Tabela 1).

Tabela 1. Distribuição dos produtores segundo o tipo de mão-de-obra predominante da unidade produtiva.

\begin{tabular}{lll}
\hline Mão-de-obra & $\mathbf{N}^{\mathbf{0}}$ de produtores & Frequência (\%) \\
\hline Familiar & 59 & 85,5 \\
Assalariada & 8 & 11,5 \\
Familiar+Assalariada & 2 & 3,0 \\
Total & 69 & 100,0 \\
\hline Fonte: Elaborado pelos autores (2017). & &
\end{tabular}

Com relação à mão-de-obra utilizada nas unidades produtivas amostradas identificou-se que $85,50 \%$ das mesmas utilizavam exclusivamente mão-de-obra familiar e $11,50 \%$ utilizavam trabalhadores temporários, na forma assalariada, característica esta predominante na colheita da cultura da banana. Aos trabalhadores temporários, o valor médio pago pela diária era de $\mathrm{R} \$$ 70,00. Assim, pode-se caracterizar o agricultor residente na APA de Guaratuba como tipicamente familiar, pois a maior parte emprega mão-de-obra familiar e, apenas quando necessário é contratado trabalhador temporário.

As famílias dos entrevistados têm a leve predominância de homens com mais de 16 anos, como indicado pela Tabela 2 , uma realidade comum na zona rural.

Tabela 2. Distribuição dos produtores, segundo o gênero e grupo etário.

\begin{tabular}{lll}
\hline Gênero & $\mathbf{N}^{\circ}$ de produtores & Frequência (\%) \\
\hline Feminino (maior de 16 anos) & 110 & 39 \\
Masculino (maior de 16 anos) & 114 & 40 \\
Crianças (até 16 anos) & 60 & 21 \\
Total & 284 & 100 \\
\hline
\end{tabular}

Fonte: Elaborado pelos autores (2017)

Do total de 284 pessoas identificadas nas entrevistas os produtores afirmaram que apenas $73(25,7 \%)$ irão permanecer na propriedade nos próximos 10 anos, muitas vezes motivados pela falta de oportunidade no campo, dificuldade de acesso ou carência de saúde e 
educação para a família. A idade dos produtores entrevistados variou de 20 a 81 anos como mostra a Figura 1.

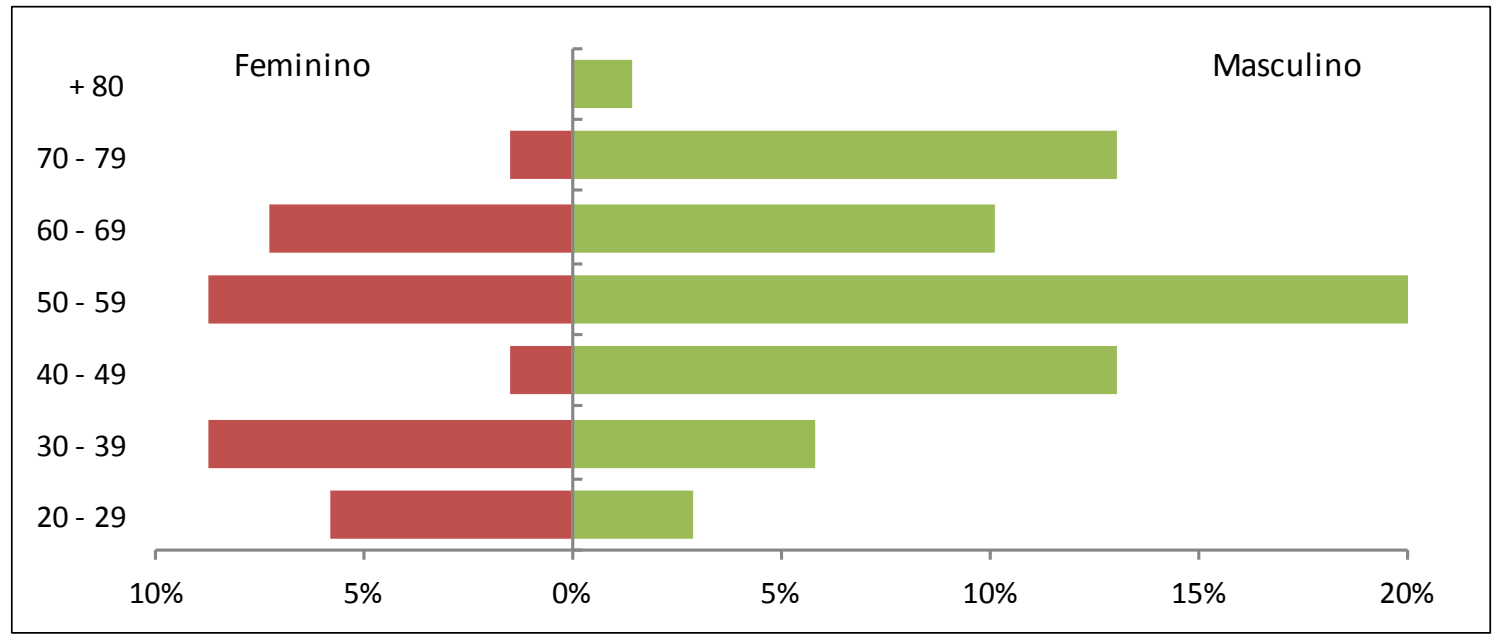

Figura 1. Faixa etária dos entrevistados. Fonte: Elaborado pelos autores (2017).

$\mathrm{Na}$ interpretação da pirâmide etária evidencia-se a presença de jovens produtores rurais, um fator importante em relação à possibilidade na adoção de tecnologias modernas e na manutenção das gerações no campo. Outro ponto importante no perfil dos entrevistados foi a declaração de profissão/ocupação onde a maioria dos entrevistados $(71,40 \%)$ se declarou como lavrador(a) ou agricultor(a).

Quanto ao nível de escolaridade dos produtores (Tabela 3), 47,14\% apresentam nível fundamental incompleto. Freitas e Bacha (2004) destacam que, no contexto brasileiro, é possível inferir que com maior nível de educação, os produtores tenham maiores habilidades empresariais, podendo adequar seus planos de produção às novas tecnologias e técnicas de cultivo.

Tabela 3. Distribuição dos produtores, segundo o nível de escolaridade.

\begin{tabular}{lrr}
\hline Nível de escolaridade & $\mathbf{N}^{\mathbf{0}}$ de produtores & Frequência (\%) \\
\hline Analfabeto & 3 & 4,29 \\
Sabe assinar & 1 & 1,43 \\
Alfabetizado & 5 & $\mathbf{7 , 1 5}$ \\
Fundamental completo & 10 & 14,28 \\
Fundamental Incompleto & 33 & 47,14 \\
Médio completo & 11 & 15,72 \\
Médio incompleto & 2 & 2,85 \\
Superior incompleto & 0 & 0 \\
Superior completo & 5 & $\mathbf{7 , 1 4}$ \\
Total & $\mathbf{7 0}$ & $\mathbf{1 0 0 , 0 0}$ \\
\hline
\end{tabular}

Segundo o trabalho "Estudos e pesquisas sobre o perfil do produtor rural no contexto brasileiro" desenvolvido pelo SEBRAE (2012), os produtores rurais têm escolaridade concentrada em "Ensino Fundamental Incompleto" (81,4\%). Pouco mais de 10\% deles têm Ensino Médio completo ou mais, sendo um público bem menos escolarizado que os empreendedores urbanos, corroborando os dados da pesquisa.

Quanto ao aceso à informação, cinco entrevistados, das localidades Rasgado, São Joãozinho, Rio do Saco e Pedra Branca do Araraquara informaram que não têm acesso ao 
serviço de energia elétrica, considerada como investimento público obrigatório pela Lei no 8.171/91, devendo, assim, ser disponibilizada pelo Poder Público ao homem do campo para oferecer-Ihe condições para sua plena capacitação, desenvolvimento e bem-estar. Os demais entrevistados, constituindo de $92,85 \%$ do total, indicaram possuir uma televisão como fonte de entretenimento e informação, $72,85 \%$ possuíam rádio, $51,42 \%$ possui dispunham de telefone celular e $10 \%$ tinham acesso à internet.

Com relação à origem da água para consumo humano, os resultados mostram que $42,85 \%$ das famílias entrevistadas têm como fonte de água as nascentes ou poços naturais; $31,42 \%$ possuem poços artesianos ou semiartesianos e $28,57 \%$ utilizam rios e córregos para seu abastecimento de água. Esta constatação é considerada normal, uma vez que a região possui uma densa rede de drenagem principalmente ao longo de suas duas maiores bacias hidrográficas, que são também as maiores contribuintes da Baía de Guaratuba: a bacia do rio Cubatão, que drena uma área de mais de 100.000 hectares, e a bacia do Rio São João, que drena uma área de mais de 33.000 hectares (PARANA, 2006).

\section{Questões econômicas}

A produção animal, presente em $64,30 \%$ das propriedades entrevistadas (Figura 2), tem como finalidade principal $(72,85 \%)$ o próprio consumo das famílias, onde se destaca a criação de aves.

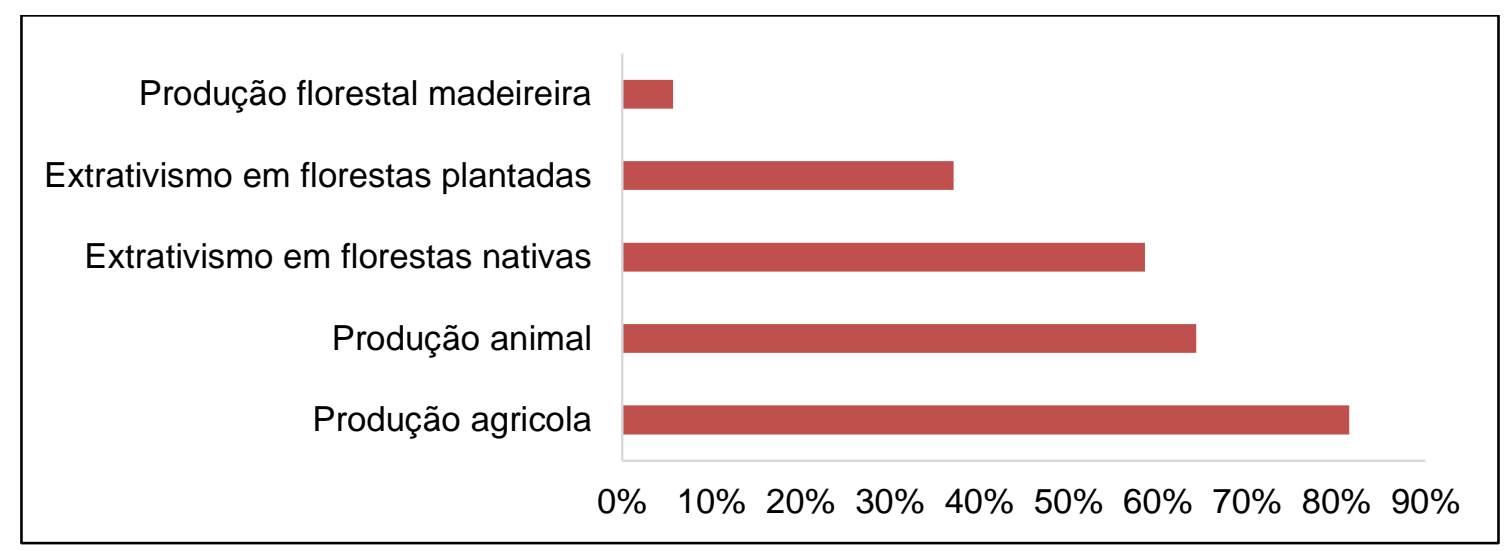

Figura 2. Tipos de produção existentes na APA de Guaratuba Fonte: Elaborado pelos autores (2017)

O sistema de produção agrícola está presente em mais de $81,40 \%$ das propriedades visitadas, sendo que a banana é a principal cultura da região $(37,86 \%)$, seguida da mandioca $(27,18 \%)$, conforme a Tabela 4.

Tabela 4. Atividade agrícola presente na APA de Guaratuba.

\begin{tabular}{lrr}
\hline \multirow{2}{*}{ Cultura } & & Frequência \\
\cline { 2 - 3 } & Absoluta & Relativa (\%) \\
\hline Banana & 39 & 37,86 \\
Demais frutíferas & 4 & 3,88 \\
Mandioca & 28 & 27,18 \\
Demais olerícolas & 25 & 24,27 \\
Arroz & 3 & 2,91 \\
Café & 2 & 1,94 \\
Cogumelo & 1 & 0,97 \\
Cana-de-acúçar & 1 & 0,97 \\
\hline TOTAL & 103 & 100,00 \\
\hline Fonte: Elaborado pelos autores (2017) & &
\end{tabular}

Cadernos de Pesquisa [ISSN 1677-5600]. Santa Cruz do Sul, v. 29, n. 2, p. 55-65, mai./ago. 2017 https://online.unisc.br/seer/index.php/cadpesquisa/index 
No que se refere à produção florestal, esta pode ser dividida em extrativismo em florestas nativas $(58,60 \%)$, extrativismo em florestas plantadas $(37,10 \%)$ e em produção madeireira de florestas plantadas para construção e reparos de benfeitorias nas propriedades $(5,71 \%)$.

Do total das 70 famílias entrevistadas, $85,71 \%$ fazem uso ou comercialização de produto florestal não madeireiro. A participação das famílias na extração e beneficiamentos dos produtos não madeireiros, nativos e cultivados, por unidade de gestão, é apresentada na Tabela 5 por unidade de gestão.

Tabela 5. Número de famílias por tipo de produto não madeireiro.

\begin{tabular}{|c|c|c|c|c|c|c|c|c|c|}
\hline \multirow[t]{2}{*}{ Produto } & \multicolumn{2}{|c|}{ Caovi-Limeira } & \multicolumn{2}{|c|}{ Morro Grande } & \multicolumn{2}{|c|}{$\begin{array}{l}\text { Estrada do } \\
\text { Castelhano }\end{array}$} & \multicolumn{2}{|c|}{$\begin{array}{c}\text { Baia de } \\
\text { Guaratuba }\end{array}$} & \multirow[t]{2}{*}{ TOTAL } \\
\hline & Abs. & $\%$ & Abs. & $\%$ & Abs. & $\%$ & Abs. & $\%$ & \\
\hline \multicolumn{10}{|l|}{$\begin{array}{l}\text { ESPÉCIES } \\
\text { NATIVAS }\end{array}$} \\
\hline Cipó-Preto & 3 & 23,1 & 8 & 61,5 & 0 & 0 & 2 & 15,4 & 13 \\
\hline $\begin{array}{l}\text { Cipó- } \\
\text { Timbopeva }\end{array}$ & 1 & 100 & 0 & 0 & 0 & 0 & 0 & 0 & 1 \\
\hline Musgo & 0 & 0 & 17 & 100 & 0 & 0 & 0 & 0 & 17 \\
\hline Guaricana & 10 & 66,6 & 0 & 0 & 4 & 26,6 & 1 & 6,8 & 15 \\
\hline Palmito Juçara & 2 & 0 & 1 & 0 & 0 & 0 & 0 & 0 & 3 \\
\hline Urucum & 0 & 0 & 1 & 50 & 0 & 0 & 1 & 50 & 2 \\
\hline \multicolumn{10}{|l|}{$\begin{array}{l}\text { ESPÉCIES } \\
\text { CULTIVADAS }\end{array}$} \\
\hline $\begin{array}{l}\text { Palmeira (Real } \\
\text { e Imperial) }\end{array}$ & 9 & 56,3 & 3 & 18,7 & 2 & 12,5 & 2 & 12,5 & 16 \\
\hline Pupunha & 8 & 61,5 & 3 & 23,1 & 2 & 15,4 & 0 & 0 & 13 \\
\hline TOTAL & & & & & & & & & 80 \\
\hline
\end{tabular}

Os resultados da Tabela 5 ilustram uma divisão dos produtos por unidade de gestão. É possível observar que a totalidade dos extratores de musgo pertence às comunidades da Linha Morro Grande. Já os coletores de folha de Guaricana predominam nas comunidades da Linha Caovi-Limeira e Estrada do Castelhano.

Esse fato ocorre, principalmente, devido aos diferentes tipos de relevo encontrados na APA de Guaratuba, pois as comunidades da Linha Caovi-Limeira e Estrada do Castelhano encontram-se no entorno e na encosta da Serra do Mar, com características favoráveis a dispersão da Geonoma gamiova. Já as comunidades da linha Morro Grande e a Baia de Guaratuba estão localizadas na porção litorânea da APA, especialmente em locais de solo arenoso úmido a encharcado e sem cobertura arbórea ("brejos de restinga") (NEGRELLE et al., 2014) que favorece o surgimento do musgo Sphagnum spp.

Por outro lado, devido à característica de hemiepífita do gênero Philodendro, ao qual pertence o cipó-preto e o cipó-timbopeva, a extração destes produtos não está vinculada a um tipo específico de relevo não sendo realizada apenas na Estrada do Castelhano. É possível observar, ainda, que o cultivo de produtos florestais não madeireiros como as Palmeiras Real e Imperial e a Pupunha predominam na linha Caovi-Limeira devido as melhores condições de acesso a BR, constante manutenção das estradas por parte das prefeituras para o escoamento da produção e presença de maiores concentrações de terra. 


\section{Iniciativas associativas e ações de fomento}

Em relação à participação e organização social das famílias estudadas, observou-se que os Guajus, forma tradicional de organização social das comunidades caiçaras, ainda ocorrem, porém de uma forma mais restrita. As comunidades que ainda mantêm essa tradição são: Riozinho, Jundiaquara, São Joãozinho, Empanturrado, Pedra Branca do Araraquara, Rio Bonito e Parati. Esses trabalhos coletivos ocorrem principalmente no plantio da mandioca.

A participação das famílias em organizações nas comunidades, como igrejas e associações foi relatada em $47,14 \%$ das entrevistas, sendo que a maioria (70\%) participa nos grupos de igreja. As associações de moradores, citada por $21 \%$ dos entrevistados, estão presente em quatro comunidades (Parati, Pedra Branca do Araraquara, Potreiro e Rio Bonito) como forma de organização dos moradores na solicitação de serviços essenciais como iluminação pública, recuperação de estradas e transporte escolar.

A associação dos bananicultores, presente nas comunidades onde é predominante a cultura da Banana (Caovi, Castelhano, Cubatão e Pai Paulo), é utilizada principalmente para assistência técnica, compra de insumos na produção e emissão do Certificado Fitossanitário de Origem (CFO). Já a associação dos piscicultores foi criada na comunidade Pedra Branca do Araraquara com a finalidade de buscar apoio na construção de tanques e assistência para produção de peixes junto a Empresa Paranaense de Assistência Técnica e Extensão Rural EMATER/Guaratuba - e a Secretaria da Agricultura e Abastecimento (SEAB). Evidenciou-se que organizações para comercialização ou produção de produtos florestais não madeireiros não foram identificadas em nenhuma das comunidades visitadas.

O crédito rural, especialmente representado pelo Programa de Fortalecimento da Agricultura Familiar (PRONAF) investimento e custeio, apesar de ter seu acesso facilitado nos últimos anos segundo alguns entrevistados, foi acessado por apenas $24,3 \%$ dos entrevistados, que utilizaram o recurso principalmente para compra de maquinários e infraestrutura de produção, ressaltando que $70 \%$ dos entrevistados são bananicultores.

Os entrevistados relataram que, em virtude do processo burocrático, da necessidade de documentação da terra e de garantia por avalista e o curto prazo de pagamento são fatores que dificultam o acesso ao crédito, fato este também evidenciado nos trabalhos de Sonda (2002) e Balzon (2006). Corroborando com o exposto, Miranda e Gomes (2016) citam que as maiores limitações do PRONAF têm sido a baixa abrangência em termos de desigualdade na distribuição regional dos recursos; o acesso facilitado para agricultores mais capitalizados e para aqueles que possuem propriedade familiar "eficiente" em detrimento dos mais fragilizados. Além disso, a autora cita o modelo de agricultura estimulado via concessão de financiamentos aponta para um baixo volume de crédito destinado à agricultura familiar, entre outros aspectos.

No que tange à assistência técnica, $41,42 \%$ dos entrevistados recebem o assessoramento principalmente da EMATER, SEAB, EPAGRI (Empresa de Pesquisa Agropecuária e Extensão Rural de Santa Catarina) e de Universidades da região. Perguntados sobre o que os técnicos fazem durante a visita, as respostas foram agrupadas em quatro grandes grupos: acompanhamento da produção $(48,27 \%)$, informação e divulgação de programas do governo $(37,95 \%)$, auxílio na compra de insumos (6,89\%) e serviços essenciais $(6,89 \%)$. Dos $58,57 \%$ que não recebem assistência, 85,36\% afirmaram que gostariam de ter acompanhamento técnico em suas propriedades. Ferreira (2010) constatou em estudo realizado na mesma área de estudo que há precariedades no acesso ás estradas, além disso comunicação, saúde, escolas e assistência técnica não chegam a essas comunidades, mas a fiscalização está sempre presente.

\section{Conclusão e recomendações}

Os moradores das quatro unidades de gestão estudadas são majoritariamente caracterizados como tipicamente de unidade familiar, com produção animal para consumo 
próprio, produção agrícola como principal fonte de renda, especialmente a produção de banana, e tendo como renda extra o extrativismo em florestas nativas.

No que diz respeito às questões econômicas a principal atividade agrícola da região é a banana seguida da mandioca. A produção florestal é bastante expressiva na região tanto de florestas nativas quanto de florestas cultivadas. O uso e comercialização de seis produtos florestais não madeireiros está presente em todas as comunidades estudadas e deve ser considerado como elemento chave na diversificação e possibilidade de aumento de renda das comunidades da região.

No que tange à questão territorial é evidente a necessidade do aperfeiçoamento dos processos de produção, buscando eficiência produtiva e econômica, como forma de melhor utilizar o reduzido espaço territorial, uma vez que sua população tende a área disponível para produção tem diminuído com a criação de unidades de conservação de proteção integral no seu entorno. A regularização fundiária é imprescindível para o alcance dos pequenos produtores aos programas de incentivo à produção do Governo e a definição clara dos seus limites.

Com relação aos aspectos sociais nas estruturas sociais locais homens e mulheres se equilibram em termos de deveres e funções e os jovens buscam alternativas para permanecer no campo. Os serviços básicos de água e luz ainda são negados às comunidades mais remotas.

O crédito rural, assistência técnica e associativismo/cooperativismo estão presentes nas comunidades, no entanto, de forma insuficiente e com foco especial na cultura da banana. É necessário maior planejamento e apoio das instituições em facilitar e/ou auxiliar os moradores, apresentando indicações que agreguem renda às famílias principalmente no que tange aos produtos florestais não madeireiros.

É imperiosa a participação dos moradores das comunidades da APA de Guaratuba nas decisões do conselho gestor a fim de tornar mais efetiva a gestão das áreas protegidas. Recomenda-se que a elaboração de políticas públicas seja coerente com a realidade local, analisando as diferenças culturais, sócio-políticas e econômicas das comunidades, devendo para isso fortalecer as instituições locais, lograr o engajamento de indivíduos e organizações que possam criar a atmosfera social, econômica, legal e institucional que assegurem a proteção da biodiversidade e o respeito à cultura das comunidades locais.

\section{Referências}

1. BALZON, R. D. Avaliação econômica dos produtos florestais não madeiráveis na Área de Proteção Ambiental - APA de Guaratuba - Paraná. Tese apresentada ao Curso de Graduação em Engenharia Florestal. Setor de Ciências Agrárias.

2. Universidade Federal do Paraná, como requisito parcial à obtenção do titulo de Doutor em Ciências Florestais. Curitiba, 2006.

3. BONI, V.; QUARESMA, S.J. Aprendendo a entrevistar: como fazer entrevistas em Ciências Sociais. Revista Eletrônica dos Pós-Graduandos em Sociologia Política da UFSC. Vol. 2 no 1 (3), janeiro-julho/2005, p. 68-80

4. FERREIRA, M. R. Comunidades rurais de Guaratuba-Paraná: os limites e as possibilidades da opção extrativista como meio de vida no contexto do desenvolvimento rural sustentável. 222 f. Tese (Doutorado em Agronomia) - Universidade Federal do Paraná. Curitiba, 2010.

5. FOOD AND AGRICULTURES ORGANIZATION (FAO); PROGRAM ON FORESTS (PROFOR). Framework for assessing and monitoring forest governance. Roma, 2011. Disponível em: <http://www.fao.org/docrep/014/i2227e/i2227e00.pdf> Acesso em: abr. 2014. 
6. FREITAS, C. A.; BACHA, C. J. C.; Contribuição do capital humano para o crescimento agropecuário brasileiro, período de 1970 a 1996. Revista Brasileira de Economia, Rio de Janeiro, v. 59, n.4, 2004.

7. LEITE, S.; HEREDIA, B.; MEDEIROS, L.; PALMEIRA, M.; CINTRÃO, R. Impactos dos assentamentos: um estudo sobre o meio rural brasileiro / Brasília: Instituto Interamericano de Cooperação para a Agricultura. Núcleo de Estudos Agrários e Desenvolvimento Rural: São Paulo: Editora UNESP, 2004.

8. MATTAR, F. Pesquisa de marketing. Ed. Atlas. 1996.

9. MIRANDA, D. L. R.; GOMES, B. M. A. Programa nacional de fortalecimento da agricultura familiar: trajetórias e desafios no Vale do Ribeira, Brasil. Soc. \& Nat., Uberlândia, 28 (3): 397-408, set/dez/2016.

10. NEGRELLE, R. R. B.; BORDIGNON, S.E.; FERREIRA, M.R.; SAMPAIO, L.K. Extrativismo e comercialização de Sphagnum (veludo): características, implicações socioeconômicas e ecológicas e perspectivas. Revista Brasileira de Horticultura Ornamental. Vol 20, n1, 2014, p53-66.

11. OLIVEIRA, J. A. P. Desafios do planejamento em políticas públicas: diferentes visões e práticas. Revista de Administração Pública, Rio de Janeiro:40(1):273-88, Mar./Abr. 2006

12. PARANÁ, Secretaria de Estado do Meio Ambiente e Recursos Hídricos. Instituto Ambiental do Paraná. Diretoria de Biodiversidade e Áreas Protegidas. Plano de Manejo da Área de Proteção Ambiental de Guaratuba. Curitiba, Fevereiro de 2006.

13. SEBRAE. Serviço Brasileiro de Apoio às Micro e Pequenas Empresas - Sebrae Unidade de Capacitação Empresarial - UCE. Perfil do produtor rural. 2012.

14. SIMÕES, L. L.; LINO, C.F. 2002. (org.) Sustentável Mata Atlântica: a exploração de seus recursos florestais. São Paulo, Editora SENAC. 215p.

15. SONDA, C. Comunidades rurais tradicionais da área de proteção ambiental de Guaratuba: caracterização sócio-econômica e utilização dos recursos vegetais silvestres. CURITIBA, 192 p, 2002. Tese (Doutorado em Engenharia Florestal) Programa de PósGraduação em Engenharia Florestal. Universidade Federal do Paraná. 